\title{
As eleições municipais no Brasil: uma análise comparativa (1982-2000)*
}

\author{
David Fleischer \\ Departamento de Ciência Política, Universidade de Brasília
}

\begin{abstract}
Resumo
Este artigo analisa os resultados do primeiro e segundo turnos da eleição municipal de 2000 no Brasil. Enfoca o desempenho de cada um dos principais partidos e de alguns dos principais candidatos, nas regiões do país e nas principais cidades, analisa o desempenho geral das candidatas mulheres, e procura traçar considerações sobre o impacto dos resultados no cenário político das eleições gerais de 2002.
\end{abstract}

Palavras-chave: eleições municipais 2000, partidos políticos, candidatos, Brasil

\begin{abstract}
This article analyses the electoral results for the first round and second round of the 2000 local elections in Brazil. It focuses on the performance of each of the main political parties and some of the major candidates, in the country regions and the main cities, it analyses the general performance of women candidates, and the author searchs to make some considerations about the impact of the electoral results on the political scenery of the 2002 general elections.
\end{abstract}

Key words: 2000 local elections, political parties, candidates, Brazil

* - Versão modificada de trabalho apresentado no XXV Encontro Anual da ANPOCS, Caxambú, MG, 16 a 20 de outubro de 2001. O autor agradece os comentários e sugestões de Rogério Schmitt, Maria D’Álva Kinzo, Leôncio Martins Rodrigues, Argelina Figueiredo, Alberto Almeida, André Marenco dos Santos e David Samuels. 
“All politics is local." Tip O'Neill

Mais de um ano após o primeiro e segundo turnos das eleições municipais de 2000, a poeira já assentou o suficiente para uma análise mais fria dos resultados e a reflexão sobre algumas das conseqüências. Quais as lições e recados que os 108 milhões de eleitores deram para a classe política, os partidos, os governos, e ao país? Quais as conseqüências para as eleições gerais em 2002?

\section{Introdução}

Logo no dia seguinte à eleição - 2 de outubro -, a cobertura e análise do processo eleitoral da Rede de TV CNN em Espanhol, do Rio de Janeiro, colocou que "a esquerda ganhou e a direita também". No final das contas, alguém perdeu?

O Brasil mostrou a sua maturidade com as urnas eletrônicas e suas 5.559 programações específicas por todo o país. Do modo geral, o eleitor brasileiro, mesmo o mais humilde manejou o teclado com êxito. Tiveram fim definitivo as emoções das mesas apuradoras, com os escrutinadores "cantando" os votos cédula por cédula, assim como as incontáveis recontagens solicitadas pelos inconformados perdedores.

Em comparação com a eleição municipal de 1996, as quatro novidades neste pleito foram: 1) a possível reeleição imediata dos prefeitos eleitos em 1996, mediante emenda constitucional aprovada em 1997; 2) a universalização das urnas eletrônicas, que em 1996 foram experimentadas pela primeira vez em umas 50 cidades maiores; 3) o aumento das cotas para candidatas a vereadora, de $20 \%$ para 30\%; e 4) a alteração do cálculo do quociente eleitoral para a eleição proporcional (vereador), onde os votos em branco deixaram de ser considerados válidos.

Ao todo, 30 partidos estavam habilitados a lançar candidatos às 5.559 vagas para prefeito e 65.805 para vereador. Destes, 24 alcançaram pelo menos uma prefeitura, e 29 uma ou mais vagas de vereador.

Das 26 capitais, 15 pleitos foram decididos em $1^{\circ}$ turno, ficando 11 para o $2^{\circ}$ turno. Nas outras 36 cidades maiores, passíveis de $2^{\circ}$ turno, 20 foram para 0 segundo turno. Este resultado não foi muito diferente do que o resultado do pleito de 1996, quando 14 capitais e 17 grandes cidades realizaram eleições de $2^{\circ}$ turno.

A comparação dos indicadores eleitorais básicos das eleições de 1996 e 2000 no Quadro 1 mostra que os níveis de alistamento são praticamente iguais, porém a abstenção de $14,81 \%$ em 2000 foi menor de que os 17,91\% registrados em 1996. Embora a proporção de votantes fosse maior em 2000, as proporções de votos válidos, em branco e nulos para prefeito são praticamente iguais.

As diferenças significativas estão nas duas eleições para vereador. Comparado com o pleito de 1996, em 2000 a proporção de votos válidos aumentou de $86,49 \%$ para $93,91 \%$, enquanto os votos em branco e nulos diminuíram de 
$13,51 \%$ para $6,09 \%$. Sem dúvida, este fenômeno se deve em grande parte à utilização da urna eletrônica em todo o Brasil em 2000, enquanto esta técnica foi experimentada em apenas 51 das maiores cidades em 1996.

\section{O desempenho dos partidos no primeiro turno}

A análise que segue nos Quadros 2 a 8 avalia o desempenho dos partidos no primeiro turno nas capitais, em 62 cidades maiores e nas cinco regiões. Estas comparações se restringem aos dez partidos considerados mais relevantes para o sistema político atual, que elegeram 5.299 prefeitos $(95,3 \%)$ e 61.046 vereadores (92,8\%).

\section{PT}

O Partido dos Trabalhadores elegeu o prefeito de apenas uma capital no primeiro turno (Dep. Marcelo Deda em Aracajú, o que foi uma surpresa), e foi para o segundo em outras 6 capitais. Nas 62 maiores cidades, elegeu 4 e disputou outras 10 no $2^{\circ}$ turno. Seu maior trunfo foi na capital paulista, onde Marta Suplicy (PT) recebeu $38 \%$ dos votos contra $17 \%$ do Paulo Maluf (PPB). A maior derrota foi no Rio, onde a Vice Governadora Benedita da Silva chegou em $3^{\circ}$ lugar, sobretudo devido às desavenças internas ao PT-RJ. Também, em Porto Alegre o ex-prefeito Tarso Genro não foi eleito no $1^{\circ}$ turno, e enfrentou um raivoso Alceu Colares (PDT) em 29 de outubro. Assim, no estado do Rio Grande do Sul, as conseqüências ficaram com o Gov. Olívio Dutra (PT-RS) que viu a sua coligação na Assembléia gaúcha minguar mais ainda com o rompimento do PDT.

Em geral, o PT elegeu 174 prefeitos (com a possibilidade de chegar a 190), quase o dobro dos 111 eleitos em 1996. Nas 62 cidades maiores, o PT tinha chances de eleger até 25 prefeitos; se incluir o PSB e o PDT, a esquerda alcançaria a metade desse conjunto de grandes cidades (31).

Em termos de votos, o PT aumentou o seu desempenho em $51 \%$ sobre 1996; mas, há um certo viés em função do grande número de votos da Marta Suplicy em São Paulo (o maior eleitorado do país). Mesmo assim, este total foi um pouco mais que metade dos 21.475.348 votos que Lula recebeu em 1998. Em 2000 o PT continua concentrado nas regiões Sudeste e Sul, mais que em 1996. (Quadros 7 e 8)

\section{PPS}

O ex-PCB teve um desempenho surpreendente, apesar da derrota de Patrícia Gomes (ex-esposa de Ciro Gomes, ex-prefeito da capital e ex-ministro da República) para a prefeitura de Fortaleza. Em grande parte, esse sucesso é devido à candidatura do Ciro Gomes à presidência em 1998 (11\% dos votos) e às muitas viagens dele e do Sen. Roberto Freire como ações de mobilização partidária em 
1999-2000.0 partido elegeu 164 prefeitos contra 32 em 1996, e disputou a prefeitura em 6 cidades no $2^{\circ}$ turno.

O PPS está concentrado no Nordeste, onde elegeu 58 prefeitos (17 no Ceará, 10 no Piauí e 10 em Sergipe) e conquistou 54 prefeituras no Sudeste (31 em São Paulo e 22 em Minas Gerais). Porém, a maioria das cidades ganhas são pequenas ou médias. Ao todo, os votos recebidos pelo PPS foram seis vezes maior do que em 1996, embora esse número seja menos da metade dos 7.426 .235 votos obtidos por Ciro Gomes em 1998. Esses dados sugerem pouco desgaste à candidatura presidencial de Ciro Gomes em 2002.

\section{PSDB}

Apesar da derrota para a prefeitura de São Paulo, o PSDB se manteve no mesmo nível de 1996, um resultado muito melhor do que a maioria das previsões. Os tucanos elegeram 4 prefeitos de capitais em $1^{\circ}$ turno e disputaram mais uma prefeitura no $2^{\circ}$ turno (Belo Horizonte - no quintal político do Gov. Itamar Franco). Nas 62 maiores cidades, o PSDB ganhou 9 prefeituras e disputou outras 8 em 29 de outubro, no $2^{\circ}$ turno.

No nível nacional, o partido elegeu 983 prefeitos contra 910 eleitos em 1996. Do total de eleitos, $34,8 \%$ estão concentrados na Região Sudeste. Destes 343, encontramos 177 em São Paulo e outros 136 em Minas Gerais. Em 2000, o PSDB tomou o lugar do PMDB como o maior partido na Região Centro-Oeste. Nesse ano, obteve a maior votação partidária; porém, isso significou somente 3.39\% de votos a mais em relação a 1996 - um percentual menor que o aumento "vegetativo" de $14 \%$ entre as duas eleições.

Em 2000, a soma dos votos dos partidos aliados em 1998 (PSDB, PFL, PMDB, PPB e PTB) foi 52.364.673, bem maior que os 35.936 .918 votos recebidos por $\mathrm{FHC}$ na sua reeleição em 1998.

\section{PFL}

A liderança do Sen. Antônio Carlos Magalhães (BA) no PFL foi reforçada com a vitória dos seus candidatos em Salvador e em 289 dos 471 municípios baianos (Rothenburg \& Lago). Por outro lado, os pefelistas em Pernambuco e Paraná concorreram às prefeituras de Recife e Curitiba enfrentando no $2^{\circ}$ turno os candidatos do PT. Comparado a seus "aliados" (PSDB, PMDB e PPB), o PFL aumentou seu cacife político elegendo 1.027 prefeitos contra os 928 eleitos em 1996. Nas capitais, ganhou 2 prefeituras e nas 62 cidades maiores elegeu prefeitos em 3 e conseguiu mais 1 no $2^{\circ}$ turno de 29 de outubro. A grande maioria dos pefelistas foi eleita em cidades médias e pequenas: $43,8 \%$ destes municípios são concentrados no Nordeste, e destes 445, 125 são da Bahia. Nas outras regiões, houve mudanças no Norte e no Sul. Assim, como em 1998, o PFL manteve a sua 
forte concentração regional. Comparado à eleição de 1996, o PFL aumentou a sua votação em $28,76 \%$.

\section{PMDB}

Apesar de previsões negativas sobre seu desempenho, a situação do PMDB não se alterou e mais uma vez elegeu o maior número de prefeitos - 1.253 - um número um pouco menor que os 1.288 eleitos em 1996 (Quadro 3). O PMDB saiu das eleições locais de 2000 menos concentrado regionalmente do que o PFL ou o PSDB, com 372 prefeitos no Sudeste, 356 no Nordeste e 334 no Sul; contudo, perdeu terreno no Norte e no Centro-Oeste. Seu desempenho nas capitais foi um pouco aquém do de 1996, mas foi melhor nas 62 cidades maiores e disputou o $2^{\circ}$ turno em 9 destas. Seu total de votos em 2000 aumentou apenas 4,26\% em relação a 1996, ficando em $2^{\circ}$ lugar, depois do PSDB. Embora o PMDB tenha mantido uma sólida base municipal, não manteve a mesma penetração nas maiores cidades que tinha o MDB nos anos 1970, ou o PMDB em 1982 e 1986.

\section{PPB}

O desempenho do PPB nas eleições de 2000 acompanhou paralelamente o do seu líder, Paulo Maluf em São Paulo. Este partido, sucessor da ARENA, PDS e PPR, obteve um número muito próximo de cidades conquistadas em 1996 (617 contra 624). Porém, perdeu terreno nas capitais e nas 62 cidades maiores, e o seu total de votos diminuiu em 30.32\%. Regionalmente, o PPB sofreu as maiores perdas no Norte e Sudeste, mas avançou no Sul e Centro-Oeste; embora esteja muito concentrado na região Sul (44,7\%). O desempenho de Paulo Maluf em São Paulo em 2000, 17,4\% dos votos, foi muito fraco comparado com os $48,9 \%$ de votos recebidos por ele no $1^{\circ}$ turno em 1992, ou os $48,3 \%$ de votos do seu sucessor indicado - Celso Pitta - em 1996. Com o possível esvaziamento da liderança de Paulo Maluf, os pepebistas do Sul podem vir a assumir a liderança do partido em nível nacional em 2002.

\section{PDT}

Depois de 20 anos como o líder inconteste do PDT, é possível que a eleição de 2000 represente uma despedida para Leonel Brizola, depois de 53 anos de vida política. Brizola quebrou a aliança PDT-PT estabelecida em 1998, recusou apoiar a candidata do PT, no Rio de Janeiro, e lançou-se candidato à prefeitura daquela cidade. O ex-governador obteve um pífio $4^{\circ}$ lugar, e "jurou" expulsar o Gov. Anthony Garotinho do PDT por alta traição e infidelidade partidária. Nas urnas, o PDT sofreu o maior revés entre os partidos aqui analisados - especialmente nas regiões Sul, e ainda no Nordeste e Centro-Oeste. Elegeu 287 prefeitos, um número muito aquém dos 435 eleitos em 1996. Ao nível nacional, a sua votação em 2000 foi $19,33 \%$ menor que em 1996. 
O trabalhismo democrático manteve-se muito concentrado no Sul onde elegeu 109 prefeitos (78 no Rio Grande do Sul) e 97 no Sudeste (38 em Minas Gerais e 33 no Rio de Janeiro). Elegeu dois prefeitos em capitais menores (São Luís e Porto Velho), e disputou a prefeitura de Porto Alegre em $2^{\circ}$ turno. Nas cidades maiores obteve 3 prefeituras.

\section{PSB}

Embora o total de votos do partido tenha aumentado em 37,07\% em parte por causa da votação da Luiza Erundina em São Paulo, o PSB elegeu menos prefeitos em 2000 (131) que em 1996 (150). Naquela eleição, o PSB estava muito concentrado no Nordeste (75,3\% dos prefeitos eleitos) em função do seu presidente nacional, o Gov. Miguel Arraes de Pernambuco. Em 2000, o partido sofreu uma desconcentração, obtendo $29,8 \%$ dos votos no Nordeste e $29,8 \%$ no Sudeste, avançando mais nesta região. No $1^{\circ}$ turno, elegeu 2 prefeitos nas cidades maiores, e disputou outras 2 prefeituras em 29 de outubro.

\section{PTB}

O PTB saiu fortalecido das urnas em 2000 , tendo aumentado a sua votação em 33,30\% em comparação com 1996 e o número de cidades conquistadas, de 328 para $397 . \quad$ O aumento de sua votação pode ser interpretado como fruto da votação recebida por César Maia na prefeitura do Rio de Janeiro. O partido avançou no Sudeste e encolheu no Centro-Oeste, obteve duas prefeituras de grandes cidades no $1^{\circ}$ turno e participou no $2^{\circ}$ turno em outras 3 cidades.

\section{PL}

O Partido Liberal conseguiu aumentar o seu cacife eleitoral em 2000. Elegeu 234 prefeitos contra 221 eleitos em 1996 e a sua votação cresceu 28,97\%. No entanto continua concentrado na região Sudeste e um pouco menos no Nordeste.

\section{Sobre a reeleição}

O grande mito desta eleição, a idéia de que haveria uma esmagadora reeleição dos prefeitos, foi destruído pelas urnas.

Há várias maneiras de calcular um "índice de reeleição":

1) calcular diretamente sobre o número de prefeitos eleitos;

2) determinar a porcentagem dos que realmente candidataram-se à reeleição; ou

3) no caso dos partidos, usar o número de prefeitos filiados aos mesmos antes de eleição, pois, alguns podem ter mudando de partido após a eleição em 1996.

Antes de 2000, já se observava no eleitorado brasileiro uma tendência à eleição de ex-prefeitos que, depois de um interregno, retornaram ao cargo. Em 
1996, por exemplo, 29,5\% dos eleitos eram "retornados" - tendo sido prefeitos eleitos em 1982 ou 1988 (Quadro 9).

Como se pode ver no Quadro 10, 2.069 prefeitos foram reeleitos, segundo dados compilados por Cruz Neto et al. (2000), ou 37,2\%. Esses autores não encontraram dados sobre 74 municípios no Maranhão na base de dados do TSE para 1996, e portanto identificaram apenas 68 reeleitos. Frente ao resultado inverso às expectativas mais pessimistas de que o abuso das máquinas municipais seria generalizado e de que uns $95 \%$ dos prefeitos seriam reeleitos, pode-se sugerir que o movimento no Congresso Nacional para acabar com a reeleição deve se esvaziar.

O fenômeno da reeleição apresentou-se no PSDB, com 47,1\%, no PFL com $41,2 \%$, seguido pelo PTB com 38,2\%. Um pouco aquém da média nacional de reeleitos encontramos o PMDB com $36,8 \%$, o PPB com $35,6 \%$, o PSB com $34,6 \%$ e - PL com 35\%. Houve um aumento significativo do desempenho na eleição de prefeitos em 2000 para o PT $(27,3 \%)$, o PPS $(21,1 \%)$ e os outros $(20,9 \%)$. A presença de novos candidatos conferiu-Ihes baixas taxas de reeleição. Contudo, para o PT, foi decepcionante a eleição de 49 dos seus 105 prefeitos que disputaram a reeleição (47\%). Por outro lado, o PDT elegeu 147 prefeitos a menos que em 1996, e mesmo assim a sua taxa foi relativamente baixa $(26,4 \%)$, indicando que muito dos seus veteranos eleitos em 1996 foram derrotados, e os seus novatos conquistaram outros cidades em 2000.

No Quadro 11, usamos os dados compilados por Felício \& Nakad e Franco (2000) e Macedo (2000) que encontraram 108 reeleitos em Maranhão contra os 68 encontrados por Cruz Neto et al.(2000) (no Quadro 10). Neste quadro, duas taxas de reeleição são calculadas:

1) o número de reeleitos sobre o número total de eleitos $(C / A)=37,9 \%$; e

2) o número de reeleitos sobre o número de prefeitos que realmente se candidataram à reeleição $(C / B)=55,9 \%$.

Pelos dois métodos, a reeleição teve mais resultado no Nordeste $(47,5 \%$ / 64,3\%), liderado pela Paraíba (51,6\% / 75,7\%) e Pernambuco (51,4\% / 77,5\%). Sergipe $(34,7 \%$ / 52,0\%) e Alagoas (45,5\% / 52,3\%) destoaram da média regional com menores índices de reeleição. As regiões com as menores taxas de reeleição foram o Centro-Oeste $(31,5 \%$ / 51,8\%) e Sudeste $(32,7 \%$ / 47,9\%). No CentroOeste, os embates entre PMDB e PSDB em Goiás (28,6\% / 52,6\%) e em Mato Grosso (31,7\% / 45,8\%) entre PSDB e PFL destacaram-se por terem sido acirrados.

Em uma análise mais detalhada, Bremaeker (2000) calculou que 2.169 prefeitos foram reeleitos $(39,4 \%)$ nos 5.505 municípios passíveis de reeleição (Quadro 12). O maior índice de reeleição ficou com a região Nordeste $(48,2 \%)$ e a menor freqüência no Sudeste (34,1\%). Esta análise destacou os 533 municípios "novos" [emancipados depois de janeiro de 1997] onde $61,2 \%$ dos prefeitos foram 
reeleitos, contra os $37,1 \%$ nos 4.972 municípios "antigos". Discriminando os municípios em dez categorias por tamanho da população, o fenômeno da reeleição assemelhou-se ao desenho de uma curva "U" - onde os mais altos índices de reeleição foram verificados nas cidades menores e maiores, e nas cidades "médias" (5.000 a 100.000 habitantes) a ocorrência foi bem menor.

\section{Sobre o desempenho das mulheres}

Em 2000, as mulheres conquistaram uma proporção ligeiramente maior de prefeituras do que em 1996 (5,7\% contra 5,5\%) (Quadro 13). Porém, não sustentaram os ganhos obtidos em 1996 na região Norte (20,5\%), onde somente $7,6 \%$ dessas prefeituras foram ocupadas por mulheres em 2000. A região Nordeste também apresentou uma queda, embora bem menor; mas, apresentou a maior proporção de prefeitas eleitas em 2000 - a mesma região com o maiores índices de reeleição, observados nos Quadros 11 e 12. A proporção de prefeitas eleitas em 2000 foi maior que em 1996 nas regiões Centro-Oeste e Sudeste, e diminuiu no Sul.

Em relação aos partidos, o PSB elegeu a maior proporção de prefeitas $(9,8 \%)$, seguido pelos outros partidos menores $(7,7 \%)$ e o PFL $(7,3 \%)$. As mulheres tiveram seu menor êxito no PDT $(2,1 \%)$, no PL $(3,8 \%)$, PT $(4,8 \%)$ e PMDB $(4,7 \%)$ (Quadro 14).

Apesar da disponibilidade de uma cota maior em 2000 nas listas proporcionais dos partidos para vereador (30\% em 2000 e $20 \%$ em 1996) a proporção de vereadoras eleitas foi quase a mesma: de 11,2\% em 1996 para $11,6 \%$ em 2000 (Quadro 15). Nas regiões Norte, Nordeste e Centro-Oeste as proporções foram quase as mesmas, tendo aumentado um pouco mais no Sudeste e Sul.

Assim como em 1996, o desempenho das mulheres na eleição proporcional, "amparadas" pelas cotas, foi melhor do que no pleito majoritário (Quadro 16). Desta vez, foi o PT que se destacou com 14,1\% de vereadoras, seguido pelo PFL, $12,1 \%$. Diferente dos outros partidos, o PT abre mais espaço nas suas diretorias nacional, estaduais e municipais para as militantes. O PDT parece ser o partido mais fechado às mulheres, sendo que somente $9,9 \%$ dos seus vereadores são mulheres.

\section{O segundo turno}

Os resultados do segundo turno realizado em 29 de outubro foram um complemento decisivo para delinear o quadro de forças políticas iniciado no primeiro turno. Dos 31 embates em municípios, sete constituíram "viradas," i.e. onde os vencedores no primeiro turno foram derrotados no segundo - as cidades de 
Recife (PE), Rio de Janeiro (RJ), Caxias do Sul (RS), Juiz de Fora (MG), Olinda (PE), Santos (SP), e São Gonçalo (RJ). (Quadro 17)

Três pleitos foram duramente disputados até a última hora, e decididos por margens apertadas:

1) o ex-prefeito César Maia (PTB) alcançou um "empate técnico" nos últimos dois dias da campanha para finalmente derrotar o Prefeito de Rio de Janeiro, Luiz Paulo Conde (PFL), por uma margem de 1\%;

2) embora segundo colocado no primeiro turno, Ângelo Vanhoni (PT), liderou as pesquisas no segundo turno mas foi superado por $1,5 \%$ numa disparada final do Prefeito de Curitiba, Cássio Taniguchi (PFL) mas o PT conquistou outras duas cidades paranaenses (Maringá e Londrina); e

3) em Recife, João Paulo (PT) venceu o Prefeito Roberto Magalhães (PFL) por apenas 5.835 votos de diferença.

Observando os resultados no Quadro 18, o PT venceu em 13 das 16 eleições que disputou, com $32,1 \%$ dos votos válidos $-50 \%$ dos quais recebidos por Marta Suplicy em São Paulo. Este resultado confirma o avanço do PT, especialmente nas cidades maiores, obtido no primeiro turno. No pleito de 29 de outubro, o PMDB ganhou em 4 cidades e o PSDB em 3. Aparentemente, o PFL foi o grande perdedor nesta eleição, onde perdeu em 4 das 5 cidades onde concorreu - inclusive nas capitais importantes de Rio de Janeiro e Recife - e seus candidatos receberam apenas $12.7 \%$ dos votos ( $60 \%$ dos quais do Conde no Rio). No cômputo geral, os partidos oposicionistas considerados de "esquerda" venceram em 21 destas 31 cidades, com 9.607.211 votos válidos (47,1\%).

Em uma avaliação mais geral dos resultados da eleição em 2000 comparada com a de 1996 no Quadro 6, a oposição aumentou seu controle das capitais de 8 para 12, mas dobrou seu placar nas 62 maiores cidades (de 10 para 20). Este grupo de seis partidos aumentou seu cacife de votos entre as eleições de 1996 e 2000 em 39,54\% (25,52\% descontado o crescimento do eleitorado). O PT aumentou sua cobertura de 111 para 187 cidades, de 2 para 6 capitais e elegeu 17 dos prefeitos das cidades maiores - com um aumento de 51,15\% dos votos recebidos - um avanço impressionante que incluiu a importante vitória da Marta Suplicy (59\%) sobre Paulo Maluf (41\%). Por outro lado, embora o PSDB e o PMDB tivessem elegido menos prefeitos de capitais que em 1996, conquistaram 12 e 10 das cidades maiores, respectivamente - mas, com quase nenhum acréscimo de votos.

Com relação ao "Brasil Urbano" (as 10 cidades maiores no Quadro 4), o PT foi o grande vencedor, triplicando o seu cacife com 27 cidades apresentadas (9 em 1996) e com a administração sobre eleitorados de 12,9 milhões de pessoas (2,34 milhões em 1997). Os outros quatro partidos da "esquerda" elegeram 22 prefeitos 
nessas grandes cidades, mas obtiveram o governo de somente 5,1 milhões de eleitores. Este resultado é muito semelhante ao de 1988, quando a "esquerda" elegeu 32 prefeitos no "Brasil Urbano" (inclusive de São Paulo) abrangendo um eleitorado de 18,5 milhões de eleitores $(55,1 \%)$.

A cúpula nacional do PSDB analisou os resultados de 2000 e identificou seu crescimento na faixa intermediária de 193 cidades entre 62.000 e 300.000 habitantes, onde obteve melhor desempenho com uns $27 \%$ dos votos. Nas 5.200 cidades com menos de 62.000 habitantes, o PMDB recebeu mais de $50 \%$ dos votos, e nas 166 cidades com mais de 300.000 habitantes o PT ficou em primeiro lugar também com $27 \%$ dos votos.

\section{Conclusões}

Quais conclusões podemos extrair desta análise sobre o processo político brasileiro e o seu sistema partidário? Quais comparações com os pleitos anteriores são pertinentes? Quais impactos podemos esperar sobre o Congresso, o governo do Pres. Fernando H. Cardoso, e a sua sucessão até o final do ano 2002?

\section{As eleições proporcionais}

Assim como na seqüência entre as eleições municipais de 1996 e eleições gerais de 1998, a nova configuração política de nível municipal (prefeitos e vereadores) em 2001 terá um impacto forte sobre as eleições para deputado em 2002. Em 1996, por exemplo, o PT dobrou o número de prefeitos eleitos e o PSDB triplicou, e como decorrência, em 1998 estes dois partidos aumentaram as suas bancadas na Câmara Federal significativamente, aproveitando as bases locais ampliadas. A bancada 'tucana' pulou de 62 para 99 deputados e o PT de 49 para 59. (Fleischer, 1998)

No pleito de 2000, 96 deputados federais (19\%) foram candidatos a prefeito ou vice-prefeito, sendo 19 deles eleitos no $2^{\circ}$ turno e outros 5 no $2^{\circ}$ turno. Assim, em $1^{\circ}$ de janeiro de 2001 , até 24 suplentes assumiram estas vagas na Câmara Federal. Dois senadores também lograram êxito.

\section{As capitais}

No cenário político definido nas capitais estaduais muitos dos 9 prefeitos das capitais reeleitos em $1^{\circ}$ de outubro e os 6 reconduzidos em 29 de outubro tornar-se-ão candidatos potenciais a governador dos seus respectivos estados, especialmente em 9 destes estados onde os governadores foram reeleitos em 1998. Até a desincompatibilização dos cargos definida em abril de 2002, esses prefeitos acumularam 5 anos e 3 meses de experiência - bem mais do que teriam se a emenda da reeleição não tivesse sido aprovada em 1997. Por outro lado, em 2000, 19 dos 26 governadores conseguiram eleger os seus "aliados" prefeitos das suas respectivas capitais. 


\section{0 espectro esquerda-direita}

As entrevistas dos parlamentares do PT divulgadas na TV na noite do domingo $1^{\circ}$ de outubro clamavam "uma vitória contundente" e "um PT consagrado" (Silva, 2000), e ainda "a rejeição total do modelo econômico do FHC". O resultado, como vimos na análise acima, foi mais equilibrado (Santos, 2000). O PT avançou bastante, especialmente nas cidades maiores, o PSB nem tanto, e o PDT regrediu. Entre os partidos situacionistas, o PFL avançou, o PSDB um pouco menos, o PMDB regrediu um pouco, e o PPB perdeu bastante terreno.

O PT avançou mais no $2^{\circ}$ turno, destacando-se os resultados em Recife e São Paulo. Por outro lado, os candidatos petistas que obtiveram maior sucesso em 2000, foram justamente mais "pragmáticos", que concentraram o seu discurso na resolução dos problemas cotidianos da cidade, e não em libelos ideológicos. Já a parte mais negativa da campanha no segundo turno foi a "apelação" do PPB e PFL contra o "perigo vermelho" tentando ligar os candidatos do PT aos velhos fantasmas do comunismo dos anos 1950 e 1960.

\section{Realinhamentos na esquerda?}

Os resultados na cidade do Rio de Janeiro previam um enfrentamento final entre o Governador Garotinho e o Índio Velho (Brizola), que confirmava então a Lei de Michels sobre a oligarquia nas organizações, com o comando total do PDT nos últimos 20 anos. Garotinho evitou perder este último round, e saiu do PDT para o PSB (antes que fosse expulso), levando 7 deputados federais e mais de 100 prefeitos. Não foi fácil outro cacique dos anos 1950 (Miguel Arraes) aceitar esta "invasão", que poderia fortalecer o socialismo brasileiro - ao mesmo tempo que fere de morte o "socialismo moreno". Ao mesmo tempo, a entrada do Garotinho para o PSB provocou a saída do prefeito reeleito de Belo Horizonte - que optou pelo PT.

Ao mesmo tempo, no início de 2001 discutiu-se a possível filiação do Gov. Itamar Franco, César Maia e/ou Anthony Garotinho ao PSB, ou a formação de um novo "partido nacionalista" juntando o PSB, o PDT de Brizola e "grupos nacionalistas" do PMDB e PSDB. Mas, nada disso se concretizou.

\section{A transparência}

Um dos recados mais fortes foi dado pelos eleitores paulistanos contra os escândalos da "máfia dos fiscais e das propinas", que foi devassado em 1999-2000, por uma Comissão Parlamentar de Inquérito na Câmara Municipal e o Ministério Público estadual, e resultou na cassação de alguns vereadores, no indiciamento de outros e condenações e prisões para um vereador e vários funcionários municipais pertencentes ao chamado "esquema Pitta-Maluf". Se esta aliança evitou o impeachment do Prefeito Celso Pitta, os eleitores estavam esperando "armados" com os seus votos nas urnas em $1^{\circ}$ de outubro. Apenas dois vereadores deste esquema foram reeleitos e todos os outros, inclusive os parentes dos acusados, foram derrotados. O PT, que liderou as investigações, aumentou a sua bancada de 9 para 
16 vereadores e o bloco anti-Pitta/Maluf pulou de 20 para 30 cadeiras. Esses resultados constituem um duro handicap para o candidato Maluf no $2^{\circ}$ turno.

\section{Sobre Paulo Maluf}

Chegando em terceiro lugar na eleição paulistana (por uma margem de apenas 6.000 votos), no domingo à noite ( $1^{\circ}$ de outubro) o Vice Governador Geraldo Alckmin disparou o seu apoio à candidata do PT, Marta Suplicy. Da Alemanha, FHC declarou a sua "simpatia" à petista, reforçada com a decisão do diretório paulista do PSDB. Outro perdedor, Sen. Romeu Tuma (PFL) também mostrou-se simpático a "candidata da honestidade e moralidade", mas foi refreado com a decisão do diretório nacional do PFL vetando qualquer apoio ao PT no $2^{\circ}$ turno. Enfrentando uma "missão [quase] impossível" no $2^{\circ}$ turno, Paulo Maluf (PPB) logo lançou o desafio da realpolitik: ao PFL: "Lembrai-vos dos seus candidatos que enfrentarão o PT no $2^{\circ}$ turno (Curitiba e Recife)"; ao PSDB/FHC: "2002 vem aí", uma clara ameaça à continuidade da coligação governista.

Mesmo sem dados para verificar a força dessas ameaças parece claro que fortalecido pelos $41 \%$ dos votos paulistanos obtidos no segundo turno, Paulo Maluf será candidato em 2002. Mesmo assim, uma eventual fusão ou formação de um bloco parlamentar entre o PPB e o PFL não teve lugar no Congresso, embora ainda seja possível em vários estados em 2002.

\section{Sobre Antônio Carlos Magalhães}

No seu estilo próprio, assim que as urnas foram fechadas no primeiro turno, o Sen. Antônio Carlos Magalhães soltou os seus primeiros "disparos" póseleitorais. Tendo aumentado o seu cacife no PFL, vis-à-vis os seus companheiros em Pernambuco e Paraná, com a sua esmagadora vitória na Bahia, almejou duramente os Ministros da Saúde e Transportes. A razão: os desembolsos préeleitorais das suas pastas nos feudos do PFL. Sabendo que os Ministros baianos estivessem talvez na mira do presidente FHC para a reforma ministerial, ocorrida em 2001 e 2002, ACM também atacou os Ministros da Justiça e Integração, e ainda debitou o bom desempenho do PT na conta dos "ministros incompetentes" do governo FHC. ACM perdeu 7 municípios baianos para o PT, inclusive cidades importantes como Itabuna e Vitória da Conquista. Seus adversários no PSDB (liderados pelo Dep. João de Almeida) elegeram 25 prefeitos e no PMDB (liderados pelo Dep. Geddel Vieira Lima) conquistaram 32 cidades (Rothenburg \& Lago:2000) Apesar de ter sido forçado a renunciar o seu mandato de Senador em maio de 2001, ACM manteve o comando do PFL baiano e é um forte candidato a Governador ou Senador em 2002..

\section{A reforma política}

Esperou-se que os resultados deste pleito municipal contribuíssem para a deliberação de vários itens da reforma política em 2001. Aparentemente, a 
reduzida taxa de reeleição dos prefeitos eleitos em 1996 ajudou reforçar a manutenção deste mecanismo para 2002. Porém, o conceito da desincompatibilização não vingou, nem para governadores, nem prefeitos.

Com a frustração em relação ao mecanismo das cotas para as mulheres nas eleições proporcionais, eram esperadas novas medidas para garantir uma proporção maior de mulheres nas casas legislativas .. especialmente a regra da lista fechada e bloqueada. Assim, cada partido é encarregado de compor a sua lista de candidatos e ordená-los previamente, e o eleitor somente vota na legenda. $\mathrm{Na}$ Argentina, por exemplo, os partidos são obrigados a colocar o nome de uma mulher pelo menos no $3^{\circ}, 5^{\circ}$ e $7^{\circ}$ lugares na lista. Na verdade, a lista fechada resolve também outras coisas, como: a fidelidade e coesão partidária, a delimitação da concorrência entre partidos e não mais entre candidatos individuais (usualmente na mesma chapa), o financiamento das campanhas centrado nos partidos (mais barato e de fácil fiscalização); a memória política do eleitor, que talvez lembre melhor pelo menos em qual partido votou na última eleição para poder cobrar melhor o desempenho deste no legislativo.

A proibição de coligações, a cláusula de barreira (5\%) nas eleições proporcionais, com algum mecanismo para preservar os partidos "históricos", uma lei de Fidelidade Partidária, onde fica proibida a troca de partido por três anos após cada eleição, e o financiamento das campanhas eram alvos da reforma política que a reforma eleitoral de 2001 não contemplou.

\section{QUADRO 1}

Indicadores eleitorais básicos: população, eleitorado, abstenção, votos em branco e nulos Brasil, 1996 e 2000.

\begin{tabular}{|c|c|c|}
\hline Indicadores & 1996 & 2000 \\
\hline População & 159.472 .820 & 169.590 .693 \\
\hline Eleitorado & 101.284 .121 & 108.493 .400 \\
\hline Alistamento & $63,51 \%$ & $63,97 \%$ \\
\hline Abstenção & $\begin{array}{c}18.143 .634 \\
17,91\end{array}$ & $\begin{array}{c}16.262 .995 \\
14,81 \%\end{array}$ \\
\hline Votantes & 80.788 .691 & 92.222 .717 \\
\hline \multicolumn{3}{|l|}{ Para Prefeito } \\
\hline Válidos & $\begin{array}{c}74.094 .960 \\
91,71 \% \\
0\end{array}$ & $\begin{array}{c}84.486 .108 \\
91,61 \% \\
0\end{array}$ \\
\hline $\begin{array}{l}\text { Votos em branco } \\
\text { e nulos }\end{array}$ & $\begin{array}{c}6.693 .731 \\
8,29 \% \\
\end{array}$ & $\begin{array}{c}7.736 .609 \\
8,39 \% \\
\end{array}$ \\
\hline \multicolumn{3}{|l|}{ Para Vereador } \\
\hline válidos & $\begin{array}{c}69.874 .259 \\
86,49 \% \\
\end{array}$ & $\begin{array}{c}86.608 .261 \\
93,91 \% \\
\end{array}$ \\
\hline $\begin{array}{l}\text { Votos em branco } \\
\text { e nulos }\end{array}$ & $\begin{array}{c}10.914 .432 \\
13,51 \%\end{array}$ & $\begin{array}{c}5.614 .456 \\
6,09 \%\end{array}$ \\
\hline
\end{tabular}

Fonte: Dados do TSE para 1996 e 2000 
OPINIÃO PÚBLICA, Campinas, Vol.VIII, nº1, 2002, pp.80-105

QUADRO 2

Resultados das eleições para prefeito, por partido: $1^{\circ}$ Turno em 2000 X 1996

\begin{tabular}{|c|c|c|c|c|c|c|c|c|}
\hline \multirow[b]{2}{*}{ Partido } & \multicolumn{4}{|c|}{2000 ( $1^{\circ}$ turno $)$} & \multicolumn{4}{|c|}{1996} \\
\hline & $\begin{array}{l}\mathbf{N}^{\circ} \text { de } \\
\text { municípios }\end{array}$ & $\%$ & Votos & $\%$ & $\begin{array}{l}\mathbf{N}^{\circ} \text { de } \\
\text { municípios }\end{array}$ & $\%$ & Votos & $\%$ \\
\hline PMDB & 1.253 & 23,8 & 13.257 .659 & 15,7 & 1.295 & 24,1 & 12.716 .976 & 17,2 \\
\hline PFL & 1.027 & 18,4 & 12.973 .544 & 15,4 & 934 & 17,4 & 10.072 .522 & 13,6 \\
\hline PSDB & 987 & 17,7 & 13.518 .346 & 16,0 & 921 & 17,1 & 13.065 .103 & 17,6 \\
\hline PPB & 617 & 11,1 & 6.812 .742 & 8,1 & 625 & 11,6 & 9.776 .752 & 13,2 \\
\hline PTB & 397 & 7,1 & 5.803 .421 & 6,9 & 382 & 7,1 & 4.354 .264 & 5,9 \\
\hline PDT & 287 & 5,1 & 5.611 .888 & 6,6 & 436 & 8,1 & 9.956 .642 & 13,4 \\
\hline $\mathrm{PL}$ & 233 & 4,2 & 2.541 .572 & 3,0 & 222 & 4,1 & 1.971 .267 & 2,6 \\
\hline PT & 174 & 3,1 & 11.938 .734 & 14,1 & 110 & 2,0 & 7.893 .509 & 10,6 \\
\hline PPS & 164 & 2,9 & 3.506 .619 & 4,2 & 33 & 0,6 & 496.150 & 0,7 \\
\hline PSB & 131 & 2,3 & 3.861 .987 & 4,6 & 150 & 2,3 & 2.816 .484 & 3,8 \\
\hline PSD & 111 & 2,0 & 1.271 .071 & 1,5 & 116 & 2,2 & 1.163 .070 & 1,6 \\
\hline PSC & 32 & 0,6 & 533.550 & 0,6 & 49 & 0,9 & 544.669 & 0,7 \\
\hline PSL & 26 & 0,5 & 283.118 & 0,3 & 11 & 0,2 & 246.887 & 0,3 \\
\hline PST & 16 & 0,3 & 176.931 & 0,2 & 09 & 0,2 & 102.474 & 0,1 \\
\hline PRP & 16 & 0,3 & 182.359 & 0,2 & 30 & 0,5 & 485.705 & 0,6 \\
\hline PMN & 14 & 0,3 & 220.231 & 0,3 & 30 & 0,5 & 443.028 & 0,6 \\
\hline PV & 13 & 0,2 & 644.638 & 0,8 & 13 & 0,2 & 242.483 & 0,3 \\
\hline PSDC & 08 & 0,1 & 139.195 & 0,2 & 02 & 0,04 & 65.163 & 0,09 \\
\hline PT do B & 06 & 0,1 & 151.914 & 0,2 & 04 & 0,07 & 141.608 & 0,2 \\
\hline $\mathrm{PHS}$ & 06 & 0,1 & 146.880 & 0,2 & & & & \\
\hline PRTB & 04 & 0,1 & 70.000 & 0,1 & 02 & 0,04 & 18.296 & 0,02 \\
\hline PRN & 03 & 0,05 & 25.464 & 0,03 & 00 & & 25.701 & 0,03 \\
\hline PTN & 02 & 0,04 & 43.193 & 0,05 & 01 & 0,02 & 23.999 & 0,03 \\
\hline PAN & 01 & 0,02 & 18.584 & 0,02 & 00 & $\cdot$ & 13.239 & 0,02 \\
\hline $\mathrm{PC}$ do $\mathrm{B}$ & 00 & . & 382.827 & 0,6 & 00 & ".'. & 191.175 & 0,03 \\
\hline PRONA & 00 & . & 235.314 & 0,5 & 01 & 0,02 & 171.855 & 0,2 \\
\hline PGT & 00 & . & 25.923 & 0,03 & 00 & 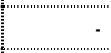 & 25.923 & 0,03 \\
\hline PSTU & 00 & & 98.387 & 0,1 & 00 & & 63.599 & 0,09 \\
\hline $\mathrm{PCB}$ & 00 & & 9.824 & 0,01 & 0 & & 12.731 & 0,02 \\
\hline PCO & 0 & & 14.116 & 0,02 & 0 & & 2.475 & 0,01 \\
\hline PSN & . & & & & 0.2 & 0,04 & 35.398 & 0,05 \\
\hline Total & 5.528 & 100,0 & 84.500 .022 & 100,0 & 5.378 & 100,0 & 74.111 .869 & 100,0 \\
\hline
\end{tabular}

Fonte: Dados do T.S.E., 27 de outubro de 2000 
QUADRO 3

Número de Prefeitos eleitos entre 1982 e 2000, por partido

\begin{tabular}{|c|c|c|c|c|c|c|c|c|c|c|}
\hline & \multicolumn{2}{|c|}{1982} & \multicolumn{2}{|c|}{1988} & \multicolumn{2}{|c|}{1992} & \multicolumn{2}{|c|}{1996} & \multicolumn{2}{|c|}{2000} \\
\hline Partido & $\mathrm{N}$ & $\%$ & $\mathrm{~N}$ & $\%$ & $\mathrm{~N}$ & $\%$ & $\mathrm{~N}$ & $\%$ & $\mathrm{~N}$ & $\%$ \\
\hline PMDB & 1.377 & 34,9 & 1.606 & 37,5 & 1.605 & 33,7 & 1.288 & 24,1 & 1.257 & 22,6 \\
\hline PDS/PPR/PPB & 2.533 & 64,3 & 446 & 10,4 & 363 & 7,6 & 624 & 11,7 & 618 & 11,1 \\
\hline PDT & 22 & 0,6 & 192 & 4,5 & 377 & 7,9 & 435 & 8,1 & 288 & 5,2 \\
\hline PTB & 07 & 0,2 & 332 & 7,7 & 303 & 6,4 & 382 & 7,1 & 398 & 7,2 \\
\hline $\mathrm{PT}$ & 02 & 0,1 & 38 & 0,9 & 54 & 1,1 & 111 & 2,1 & 187 & 3,3 \\
\hline PFL & . & $\cdots$ & 1.058 & 24,7 & 965 & 20,3 & 928 & 17,3 & 1.028 & 18,5 \\
\hline PSDB & . & $\cdots$ & 18 & 0,4 & 317 & 6,7 & 910 & 17,0 & 990 & 17,8 \\
\hline$P L$ & - & $\cdots$ & 239 & 5,6 & 165 & 3,5 & 221 & 4,1 & 234 & 4,2 \\
\hline PDC & - & $\cdots$ & 232 & 5,4 & 211 & 4,4 & . & $\cdots$ & $\cdots$ & \\
\hline PSB & - & $\cdots$ & 37 & 0,9 & 48 & 1,0 & 150 & 2,8 & 133 & 2,4 \\
\hline PJ/PRN & - & $\cdots$ & 03 & 0,1 & 98 & 2,1 & 00 & 0,0 & 03 & 0,05 \\
\hline PSC & . & $\cdots$ & 26 & 0,6 & 50 & 1,1 & 49 & 0,9 & 33 & 0,6 \\
\hline PTR & . & $\cdots$ & 08 & 0,2 & 48 & 1,0 & $\therefore$ & $\cdots$ & . & $\cdots$ \\
\hline PCB/PPS & . & $\cdots$ & 01 & 0,0 & 01 & 0,0 & 32 & 0,6 & 166 & 3,0 \\
\hline PSD & - & $\cdots$ & 02 & 0,0 & 35 & 0,7 & 116 & 2,2 & 111 & 2,0 \\
\hline PMB & . & $\cdots$ & 49 & 1,1 & . & . & . . & $\ldots$ & . . & $\cdots$ \\
\hline PST & $\cdot$. & $\cdots$ & $\cdots$ & $\cdots$ & 122 & 2,6 & 09 & 0,2 & 16 & 0,3 \\
\hline PMN &. & $\ldots$ & $\cdots$ & $\cdots$ & . & . & 30 & 0,6 & 14 & 0,3 \\
\hline PRP & . . & $\ldots$ & . & $\ldots$ & . & $\ldots$ & 30 & 0,6 & 18 & 0,3 \\
\hline Outros & $\cdot$. & $\cdots$ & 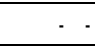 & $\cdots$ & 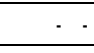 & $\cdots$ & 36 & 0,6 & 83 & 1,5 \\
\hline TOTAL & 3.941 & 100,0 & 4.287 & 100,0 & 4.762 & 100,0 & 5.351 & 100,0 & 5.559 & 100,0 \\
\hline
\end{tabular}

* - As capitais dos estados e as cidades designadas como "áreas de segurança nacional" e estações hidrominerais não elegeram prefeitos em 1982. Foram realizadas eleições especiais para prefeitura nesses 201 municípios em 15 de novembro de 1985. 
QUADRO 4

Resultados das eleições municipais no "Brasil urbano" (cem maiores cidades), 1988-2000, por partido

\begin{tabular}{|c|c|c|c|c|c|c|c|c|}
\hline & \multicolumn{2}{|c|}{1988} & \multicolumn{2}{|c|}{1992} & \multicolumn{2}{|c|}{1996} & \multicolumn{2}{|c|}{2000} \\
\hline Partido & $\mathrm{N}^{\circ}$ & Eleitorado & $\mathrm{N}^{\circ}$ & Eleitorado & $\mathrm{N}^{\circ}$ & Eleitorado & $\mathrm{N}^{\circ}$ & Eleitorado \\
\hline PMDB & $20 f$ & 4.211 .092 & $29 a$ & 9.420 .266 & $16 \mathrm{c}$ & 3.687 .305 & 15 & 3.492 .868 \\
\hline PFL & 09 & 2.373 .601 & 07 & 1.822 .170 & $08 a$ & 6.346 .293 & $09 c$ & 2.712 .234 \\
\hline PSDB & $08 \mathbf{e}$ & 3.065 .788 & $13 f$ & 3.307 .923 & 21 & 4.495 .374 & 16 & 3.505 .937 \\
\hline PDS/PPB & 10 & 1.371 .263 & $07 \mathbf{b}$ & 6.822 .597 & $11 \mathbf{b}$ & 8.462 .240 & $03 d$ & 593.281 \\
\hline PDT & $17 a$ & 8.403 .612 & $15 c$ & 4.167 .710 & 15 & 3.783 .676 & 09 & 1.611 .180 \\
\hline PTB & $12 d$ & 2.529 .370 & 05 & 1.375 .581 & 06 & 1.248 .537 & $06 a$ & 4.621 .536 \\
\hline PT & $12 \mathbf{b}$ & 9.269 .506 & $12 \mathrm{de}$ & 4.297 .722 & $09 f$ & 2.357 .134 & $27 \mathbf{b}$ & 12.918 .961 \\
\hline $\mathrm{PL}$ & 02 & 294.793 & 00 & . . & 02 & 257.567 & 01 & 482.005 \\
\hline PDC & 05 & 870.195 & 03 & 741.047 & $* *$ & . . & 00 & $\cdot \quad \cdot$ \\
\hline PSB & 03 & 857.004 & 04 & 1.021 .615 & $08 e$ & 2.528 .380 & $06 e$ & 2.245 .479 \\
\hline PRN & 02 & 373.098 & 01 & 92.062 & 00 & $\cdot \quad \cdot \quad \cdot$ & 00 & $\cdot \quad \cdot$ \\
\hline Outros & 00 & . . . & 04 & 550.629 & 04 & 452.744 & 08 & 1.434 .904 \\
\hline Total(g) & 100 & 33.619 .322 & 100 & 33.619 .322 & 100 & 33.619 .322 & 100 & 33.619 .322 \\
\hline "Esquerda"** & 32 & 18.530 .122 & 32 & 9.655 .489 & 32 & 8.669 .190 & 49 & 17.993 .466 \\
\hline$\%$ & & 55,1 & & 28,7 & & 25,8 & & 53,5 \\
\hline
\end{tabular}

a - Ganhou Rio de Janeiro

b - Ganhou São Paulo

c - Perdeu Rio de Janeiro

d - Perdeu São Paulo

e - Ganhou Belo Horizonte

f - Perdeu Belo Horizonte

g - Eleitorado em 1992

** - PDC se fundiu com o PDS para formar o PPR em 1993, que por sua vez fundiu-se com o PP para formar o PPB em 1995.

* - "Esquerda" = PT + PDT + PSB + PPS + PC do B

Fonte: Dados do TSE e (Fleischer, 1995) 


\section{QUADRO 5}

Resultados das eleições municipais* nas 26 capitais em 01 de Outubro de 2000, em ordem decrescente de população

\begin{tabular}{|c|c|c|c|c|c|c|c|c|c|c|c|c|}
\hline & Atua & & & Partidc & mais & nport & tes em & & & & & \\
\hline Cidade & EST & GOV & PREF & PMDB & PFL & PPB & PSDB & PDT & PTB & PT & PSB & $\begin{array}{l}\text { Outro } \\
\mathrm{s}\end{array}$ \\
\hline S.Paulo & SP & PSDB & PTN & & & $17 \%$ & $17 \%$ & & & $38 \%$ & & \\
\hline Rio & RJ & PDT & PFL & & $35 \%$ & & & & $23 \%$ & $22 \%$ & & \\
\hline B.Horiz. & MG & $? ?$ & PSB & $17 \%$ & & & $\underline{31 \%}$ & & & & $44 \%$ & \\
\hline Salvad. & $\mathrm{BA}$ & PFL & PFL & & $54 \%$ & & & $07 \%$ & & $35 \%$ & & \\
\hline Fortal. & CE & PSDB & PMDB & $\underline{33} \%$ & $18 \%$ & & & & & & & $30 \%$ \\
\hline & & & & & & & & & & & & \\
\hline P.Alegre & RS & $\mathrm{PT}$ & PT & & & & $16 \%$ & $20 \%$ & & $49 \%$ & & \\
\hline Curitiba & PR & PFL & PFL & $10 \%$ & $44 \%$ & & & & & $35 \%$ & & \\
\hline Recife & $\mathrm{PE}$ & PMDB & PFL & & $49 \%$ & & & & & $\underline{36} \%$ & & $11 \%$ \\
\hline Belém & PA & PSDB & PT & & & & $17 \%$ & & & $43 \%$ & & $30 \%$ \\
\hline Manaus & AM & PFL & $\mathrm{PL}$ & & & & & & & $16 \%$ & & ** \\
\hline & & & & & & & & & & & & \\
\hline Goiânia & GO & PSDB & PSDB & & & & $23 \%$ & & $30 \%$ & $37 \%$ & & \\
\hline S.Luís & MA & PFL & PDT & & & & $31 \%$ & $53 \%$ & $09 \%$ & & & \\
\hline Natal & RN & PMDB & PSB & & & & $11 \%$ & & & $31 \%$ & $57 \%$ & \\
\hline Maceió & $\mathrm{AL}$ & PSB & PSB & & & & & & & $18 \%$ & $44 \%$ & $22 \%$ \\
\hline C.Gran. & MS & $\mathrm{PT}$ & PMDB & $68 \%$ & & & & & & $21 \%$ & & $05 \%$ \\
\hline Teres. & $\mathrm{PI}$ & PMDB & PSDB & & & $04 \%$ & & $61 \%$ & & & $32 \%$ & \\
\hline J.Pess. & PB & PMDB & PMDB & $74 \%$ & & & & & & $23 \%$ & & $02 \%$ \\
\hline Aracajú & SE & PSDB & PMDB & & & & & & $23 \%$ & $52 \%$ & $22 \%$ & \\
\hline Cuiabá & MT & PSDB & PSDB & $05 \%$ & & & $56 \%$ & & & $17 \%$ & & \\
\hline Florian. & SC & PPB & PPB & $08 \%$ & & $55 \%$ & & & & & & $16 \%$ \\
\hline & & & & & & & & & & & & \\
\hline Vitoria & ES & PSDB & PSDB & & & & $13 \%$ & $69 \%$ & & & $12 \%$ & \\
\hline P.Velho & $\mathrm{RO}$ & PMDB & PSDB & & & & $12 \%$ & $42 \%$ & & & $36 \%$ & \\
\hline R.Bco. & $A C$ & PT & PMDB & $48 \%$ & & & & & & $02 \%$ & $41 \%$ & \\
\hline Palmas & TO & PFL & $\mathrm{PFL}$ & $04 \%$ & $49 \%$ & & & & & & & $48 \%$ \\
\hline Macapá & $\mathrm{AP}$ & PSB & PFL & & & $13 \%$ & & & $35 \%$ & & $36 \%$ & \\
\hline B.Vista & RR & PTB & PTB & & & $16 \%$ & $44 \%$ & & $27 \%$ & & & \\
\hline & & & & & & & & & & & & \\
\hline Primeiro & lugar & & & 04 & 05 & 02 & 04 & 02 & 00 & 05 & 04 & 01 \\
\hline Segundc & lugar & & & 00 & 00 & 01 & 01 & 01 & 05 & 08 & 02 & 06 \\
\hline Terceiro & ugar & & & 05 & 02 & 02 & 07 & 01 & 01 & 05 & 01 & 04 \\
\hline Total: $1^{0}$ & $2^{\circ}+$ & & & 09 & 07 & 05 & 12 & 04 & 06 & 18 & 07 & 11 \\
\hline Vitórias $n$ & $1^{\circ} \mathrm{tur}$ & & & 03 & 02 & 01 & 04 & 02 & 00 & 01 & 02 & 00 \\
\hline Disputol & $2^{\circ}$ tur & & & 01 & 03 & 01 & 01 & 01 & 02 & 06 & 02 & 05 \\
\hline
\end{tabular}

\section{EST $=$ Estado}

GOV = Partido do então Governador eleito em 1998. Negrito= eleito no 10 turno.

PREF = Partido do atual Prefeito eleito em 1996 (Negrito=tentou reeleição). ( turno)

* - \% do total dos votos válidos . ** - PL (47\%) \& PPS (32\%) 
OPINIÃO PÚBLICA, Campinas, Vol.VIII, nº1, 2002, pp.80-105

\section{QUADRO 6}

Desempenho dos partidos mais importantes, 1996 vs. 2000*

\begin{tabular}{|c|c|c|c|c|c|c|c|c|c|c|c|}
\hline \multirow[b]{3}{*}{ Partido } & \multicolumn{3}{|c|}{ Total Brasil } & \multicolumn{3}{|c|}{26 Capitais } & \multirow{2}{*}{\multicolumn{2}{|c|}{$\begin{array}{c}62 \text { Cidades }^{* *} \\
2000\end{array}$}} & \multirow{2}{*}{\multicolumn{3}{|c|}{ Votos recebidos (em 000) }} \\
\hline & & \multicolumn{2}{|c|}{2000} & & \multicolumn{2}{|c|}{2000} & & & & & \\
\hline & 1996 & $1^{\circ}$ & $2^{\circ}$ & 1996 & $1^{\circ}$ & $2^{\circ}$ & $1^{\circ}$ & $2^{\circ}$ & 1996 & 2000 & Mudança \\
\hline PMDB & 1288 & 1253 & 04 & 05 & 03 & 01 & 06 & 04 & 12.717 & 13.258 & $+4,25 \%$ \\
\hline PFL & 928 & 1027 & 01 & 04 & 02 & 01 & 03 & 01 & 10.073 & 12.973 & $+28,79 \%$ \\
\hline PSDB & 910 & 987 & 03 & 04 & 04 & 00 & 09 & 03 & 13.065 & 13.518 & $+3,47 \%$ \\
\hline PPB & 624 & 617 & 01 & 04 & 01 & 00 & 01 & 01 & 9.777 & 6.813 & $.30,32 \%$ \\
\hline PTB & 328 & 397 & 01 & 01 & 00 & 01 & 02 & 01 & 4.354 & 5.803 & $+33,72 \%$ \\
\hline PDT & 435 & 287 & 01 & 03 & 02 & 00 & 03 & 01 & 6.957 & 5.612 & $-19,33 \%$ \\
\hline $\mathrm{PL}$ & 221 & 233 & 01 & 00 & 00 & 01 & 00 & 01 & 1.971 & 2.542 & $+28,93 \%$ \\
\hline PT & 111 & 174 & 13 & 02 & 01 & 05 & 04 & 13 & 7.894 & 11.939 & $+51,25 \%$ \\
\hline PPS & 32 & 164 & 02 & 00 & 00 & 00 & 01 & 02 & 496 & 3.510 & $+607,43 \%$ \\
\hline PSB & 150 & 131 & 02 & 03 & 02 & 02 & 02 & 02 & 2.816 & 3.862 & $+37,12 \%$ \\
\hline Outros & 269 & 258 & 02 & 00 & 00 & 00 & 00 & 02 & 3.992 & 4.670 & $+16,98 \%$ \\
\hline TOTAL & 5.351 & 5.528 & 31 & 26 & 15 & 11 & 31 & 31 & 74.112 & 84.500 & $+14,02$ \\
\hline “Esquerda”\# & 741 & 769 & 21 & 08 & 05 & 07 & 10 & 20 & 18.598 & 25.951 & $+39,54$ \\
\hline
\end{tabular}

* - O primeiro turno em 01-OUT, e o segundo em 29-OUT de 2000.

** - Capitals e cidades com mais de 200.000 eleitores.

\# - "Esquerda" = PT + PDT + PSB + PPS + PC do B + PV

Fontes: Folha Online e dados do TSE.

\section{QUADRO 7}

Prefeitos eleitos em 2000, por partido e região (em \%)

\begin{tabular}{|c|c|c|c|c|c|c|c|}
\hline \multirow[b]{2}{*}{ Partido } & \multicolumn{5}{|c|}{ Região } & \multirow[t]{2}{*}{ Total 2000} & \multirow[t]{2}{*}{ Total 1996} \\
\hline & Norte & Nordeste & Sudeste & Sul & C.Oeste & & \\
\hline PMDB & 18,2 & 19,9 & 22,5 & 28,1 & 23,6 & 22,6 & 24,1 \\
\hline PFL & 21,6 & 24,9 & 15,5 & 13,3 & 14,9 & 18,5 & 17,3 \\
\hline PSDB & 19,6 & 16,1 & 20,7 & 10,9 & 29,9 & 17,8 & 17,0 \\
\hline PPB & 12,9 & 8,3 & 5,7 & 23,2 & 18,7 & 11,1 & 11,7 \\
\hline PDT & 4,7 & 2,6 & 5,9 & 9,2 & 3,0 & 5,1 & 8,1 \\
\hline PTB & 7,6 & 7,2 & 9,1 & 6,1 & 2,2 & 7,1 & 7,2 \\
\hline $\mathrm{PL}$ & 3,8 & 5,7 & 5,8 & 0,4 & 2,8 & 4,2 & 4,1 \\
\hline PSB & 2,7 & 3,9 & 2,4 & 0,8 & 0,2 & 2,4 & 2,8 \\
\hline PT & 4,7 & 1,2 & 4,4 & 4,9 & 3,0 & 3,3 & 2,1 \\
\hline PPS & 1,1 & 3,2 & 3,3 & 1,4 & 6,7 & 3,0 & 0,6 \\
\hline Outros* & 3,1 & 7,0 & 4,7 & 1,7 & 5,0 & 4,6 & 5,0 \\
\hline Total \% & 100,0 & 100,0 & 100,0 & 100,0 & 100,0 & 100,0 & 100,0 \\
\hline TOTAL & 449 & 1791 & 1668 & 1189 & 462 & 5559 & 5351 \\
\hline
\end{tabular}

* - PAN, PHS, PMN, PRN, PRP, PRTB, PSC, PSD, PSDC, PSL, PST, PT do B, PTN, PC do B e PV 


\section{QUADRO 8}

Prefeitos eleitos em 1996 por partido e região (em \%)

\begin{tabular}{|c|c|c|c|c|c|c|c|}
\hline \multirow[b]{2}{*}{ Partido } & \multicolumn{5}{|c|}{ Região } & \multirow{2}{*}{$\begin{array}{l}\text { Total } \\
2000\end{array}$} & \multirow{2}{*}{$\begin{array}{l}\text { Total } \\
1996\end{array}$} \\
\hline & Norte & Nordeste & Sudeste & Sul & C.Oeste & & \\
\hline PMDB & 23,5 & 19,3 & 20,8 & 31,1 & 36,5 & 24,1 & 33,7 \\
\hline PFL & 16,0 & 24,0 & 17,0 & 9,4 & 15,5 & 17,3 & 20,3 \\
\hline PSDB & 15,8 & 13,3 & 28,3 & 7,7 & 15,5 & 17,0 & 6,6 \\
\hline $\mathrm{PPB}^{*}$ & 20,5 & 8,3 & 7,5 & 20,8 & 7,7 & 11,7 & 7,6 \\
\hline PDT & 4,7 & 4,2 & 5,6 & 19,4 & 6,3 & 8,1 & 7,9 \\
\hline PTB & 7,8 & 7,8 & 6,6 & 7,0 & 6,1 & 7,2 & 6,4 \\
\hline $\mathrm{PL}$ & 2,3 & 6,7 & 4,3 & 0,5 & 4,7 & 4,1 & 3,5 \\
\hline PSB & 2,1 & 6,7 & 1,5 & 0,2 & 0,0 & 2,1 & 1,1 \\
\hline PT & 2,6 & 0,6 & 2,9 & 3,4 & 0,9 & 2,1 & 1,1 \\
\hline Outros & 4,7 & 9,1 & 5,5 & 0,5 & 7,2 & 5,6 & 11,9 \\
\hline Total\% & 100,0 & 100,0 & 100,0 & 100,0 & 100,0 & 100,0 & 100,0 \\
\hline Total & 425 & 1.682 & 1.641 & 1.159 & 444 & $\underline{5.341}$ & 4.762 \\
\hline
\end{tabular}

* - O PDS fundiu-se com o PDC em 1993 para formar o PPR, que por sua vez fundiu-se com o PP para formar o PPB em 1995.

\section{QUADRO 9}

Número de ex-prefeitos eleitos em 1996, por região

\begin{tabular}{|c|c|c|c|c|c|}
\hline & & \multicolumn{4}{|c|}{ Ex-Prefeitos Eleitos em 1996} \\
\hline Região & $\begin{array}{l}\text { Total } \\
1991^{*}\end{array}$ & $\begin{array}{l}\text { Total } \\
\text { (N) }\end{array}$ & $\begin{array}{l}\text { Total } \\
\%\end{array}$ & $\begin{array}{l}89 / 92 \# \\
\%\end{array}$ & $\begin{array}{l}83 / 88 @ \\
\%\end{array}$ \\
\hline Norte & 298 & 47 & 15,8 & 12,4 & 3,4 \\
\hline Nordeste & 1509 & 476 & 31,5 & 24,6 & 6,9 \\
\hline Sudeste & 1432 & 461 & 32,2 & 25,8 & 6,4 \\
\hline Sul & 873 & 249 & 28,5 & 20,4 & 8,1 \\
\hline Centro-Oeste & 379 & 93 & 24,5 & 16,6 & 7,9 \\
\hline BRASIL & 4491 & 1362 & 29,5 & 22,7 & 6,8 \\
\hline
\end{tabular}

* - Municípios que existiam em 1991 (antes das eleições de 1992).

\# - Ex-Prefeitos com exercício no período de 1989 a 1992.

@ - Ex-Prefeitos com exercício no período de 1983 a 1988.

Fonte: Compliado de dados do Instituto Brasileiro de Administração Municipal.

QUADRO 10

Reeleição de prefeitos em 2000, por partido

\begin{tabular}{|l|r|r|r|}
\cline { 2 - 4 } \multicolumn{1}{c|}{} & Eleitos $\mathbf{1}^{\mathbf{0}}$ turno & $\mathrm{N}^{\circ}$ de reeleitos & $\%$ de reeleitos \\
\hline PMDB & 1257 & 463 & $36,8 \%$ \\
\hline PFL & 1028 & 424 & $41,2 \%$ \\
\hline PSDB & 990 & 466 & $47,1 \%$ \\
\hline PPB & 618 & 220 & $35,6 \%$ \\
\hline PTB & 398 & 152 & $38,2 \%$ \\
\hline PDT & 288 & 76 & $26,4 \%$ \\
\hline PL & 234 & 82 & $35.0 \%$ \\
\hline PT & 187 & 51 & $27,3 \%$ \\
\hline PPS & 166 & 35 & $21,1 \%$ \\
\hline PSB & 133 & 46 & $34,6 \%$ \\
\hline Outros & 260 & 54 & $20,9 \%$ \\
\hline TOTAL & $\mathbf{5 5 5 9}$ & $\mathbf{2 0 6 9}$ & $\mathbf{3 7 , 2 \%}$ \\
\hline
\end{tabular}

* - Inclui 31 cidades do $2^{\circ}$ turno.

** - : PSD, PSC, PSL, PST, PRP, PMN, PV, PSDC,PHS, PT do B, PRTB, PRN, PTN e PAN.

Fonte: Cruz Neto et al. Para o Estado de Maranhão, não foram encontrados dados para 74 municípios na base de dados do TSE para 1996. 
QUADRO 11

Reeleição de prefeitos em 2000, por região

\begin{tabular}{|c|c|c|c|c|c|}
\hline & A & B & C & C/A & $\mathrm{C} / \mathrm{B}$ \\
\hline $\begin{array}{c}\text { Estado/ } \\
\text { Região }\end{array}$ & $\begin{array}{l}\mathrm{N}^{0} \text { de } \\
\text { munc. }\end{array}$ & $\begin{array}{l}\text { Candidato } \\
\text { à reeleição }\end{array}$ & $\begin{array}{c}\mathrm{N}^{\circ} \mathrm{de} \\
\text { reeleitos }\end{array}$ & $\begin{array}{c}\% \text { de } \\
\text { reeleitos }\end{array}$ & $\begin{array}{c}\% \text { de } \\
\text { reeleitos }\end{array}$ \\
\hline Acre & 22 & 18 & 08 & $38,0 \%$ & $44,4 \%$ \\
\hline Amazonas & 62 & 49 & 24 & $38,1 \%$ & $49,0 \%$ \\
\hline Amapá & 16 & 08 & 01 & $06,3 \%$ & $12,5 \%$ \\
\hline Pará & 143 & 113 & 50 & $35,0 \%$ & $44,2 \%$ \\
\hline Rondônia & 52 & 38 & 18 & $34,6 \%$ & $47,4 \%$ \\
\hline Roraima & 15 & 11 & 03 & $20,0 \%$ & $27,3 \%$ \\
\hline Tocantins & 139 & 101 & 59 & $42,4 \%$ & $58,4 \%$ \\
\hline Norte & 449 & 338 & 163 & $36,0 \%$ & $41,5 \%$ \\
\hline Alagoas & 102 & 88 & 47 & $46,0 \%$ & $53,4 \%$ \\
\hline Bahia & 417 & 282 & 177 & $42,4 \%$ & $62,8 \%$ \\
\hline Ceará & 184 & 140 & 93 & $50,5 \%$ & $66,4 \%$ \\
\hline Maranhão & 217 & 182 & 108 & $49,8 \%$ & $59,3 \%$ \\
\hline Paraiba & 223 & 152 & 115 & $51,6 \%$ & $75,7 \%$ \\
\hline Pernambuco & 184 & 120 & 93 & $51,4 \%$ & $77,5 \%$ \\
\hline Piauí & 222 & 182 & 112 & $50,5 \%$ & $61,5 \%$ \\
\hline R. G. Norte & 167 & 127 & 90 & $53,9 \%$ & $70,9 \%$ \\
\hline Sergipe & 75 & 50 & 26 & $34,7 \%$ & $52,0 \%$ \\
\hline Nordeste & 1791 & 1323 & 851 & $47,5 \%$ & $64,3 \%$ \\
\hline E. Santo & 78 & 46 & 17 & $21,8 \%$ & $37,0 \%$ \\
\hline Minas Gerais & 853 & 589 & 298 & $34,9 \%$ & $50,6 \%$ \\
\hline Rio de Janeiro & 92 & 78 & 38 & $41,3 \%$ & $48,7 \%$ \\
\hline São Paulo & 645 & 412 & 191 & $29,6 \%$ & $46,4 \%$ \\
\hline Sudeste & 1668 & 1125 & 544 & $32,6 \%$ & $48,4 \%$ \\
\hline Paraná & 399 & 283 & 151 & $38,1 \%$ & $53,4 \%$ \\
\hline R.G. Sul & 497 & 283 & 154 & $31,2 \%$ & $54,4 \%$ \\
\hline S. Catarina & 293 & 146 & 89 & $30,4 \%$ & $61,0 \%$ \\
\hline Sul & 1189 & 709 & 394 & $33,3 \%$ & $55,6 \%$ \\
\hline Goiás & 246 & 133 & 70 & $28,6 \%$ & $52,6 \%$ \\
\hline Mato Grosso & 139 & 96 & 44 & $31,7 \%$ & $45,8 \%$ \\
\hline M. Grosso Sul & 77 & 51 & 31 & $40,3 \%$ & $60,8 \%$ \\
\hline Centro-Oeste & 462 & 280 & 145 & $31,5 \%$ & $51,8 \%$ \\
\hline BRASIL & 5559 & 3775 & 2109* & $37,9 \%$ & $55,9 \%$ \\
\hline
\end{tabular}

* - Inclue os 31 cidades do $2^{\circ}$ turno.

Fontes: Felício \& Nakad Jr. e Franco \& Macedo.

Foram encontrados 2.109 reeleitos em função de dados mais completos para o estado de Maranhão em relação ao ano 1996 encontrados pelos autores. 
QUADRO 12

Reeleição de prefeitos em municípios "antigos" e "novos" em 2000, por tamanho e região

\begin{tabular}{|c|c|c|c|c|}
\hline \multirow{2}{*}{$\begin{array}{l}\text { População/ } \\
\text { Região }\end{array}$} & \multirow{2}{*}{$\begin{array}{l}\text { Municípios } \\
\text { “Antigos" (1) }\end{array}$} & \multirow{2}{*}{$\begin{array}{l}\text { Municípios } \\
\text { "Novos" (2) }\end{array}$} & \multicolumn{2}{|c|}{ Total (3) } \\
\hline & & & $\%$ & (N) \\
\hline Menos de 2.000 & $30,7 \%$ & $72,5 \%$ & $43,8 \%$ & 128 \\
\hline 2.000 a 5.000 & $37,5 \%$ & $63,7 \%$ & $43,3 \%$ & 1.279 \\
\hline 5.000 a 10.000 & $34,0 \%$ & $55,9 \%$ & $36,4 \%$ & 1.303 \\
\hline 10.000 a 20.000 & $36,3 \%$ & $54,5 \%$ & $37,1 \%$ & 1.395 \\
\hline 20.000 a 50.000 & $38,8 \%$ & $83,3 \%$ & $39,1 \%$ & 915 \\
\hline 50.000 a 100.000 & $39,6 \%$ & $20,0 \%$ & $39,3 \%$ & 280 \\
\hline 100.000 a 200.000 & $45,8 \%$ & . & $45,8 \%$ & 107 \\
\hline 200.000 a 500.000 & $47,9 \%$ & $\therefore$ & $47,9 \%$ & 71 \\
\hline 500.000 a 1 milhão & $73,3 \%$ & . & $73,3 \%$ & 15 \\
\hline Mais de 1 milhão & $50,0 \%$ & . & $50,0 \%$ & 12 \\
\hline Norte & $38,4 \%$ & $45,1 \%$ & $39,2 \%$ & 449 \\
\hline Nordeste & $45,6 \%$ & $65,5 \%$ & $48,2 \%$ & 1.786 \\
\hline Sudeste & $31,6 \%$ & $62,4 \%$ & $34,1 \%$ & 1.666 \\
\hline Sul & $33,3 \%$ & $60,4 \%$ & $35,6 \%$ & 1.159 \\
\hline Centro-Oeste & $33,6 \%$ & $47,4 \%$ & $34,2 \%$ & 445 \\
\hline Brasil & $37,1 \%$ & $61,2 \%$ & $39,4 \%$ & $\ldots$ \\
\hline$(\mathrm{N})$ & $(4.972)$ & $(533)$ & & (5.505) \\
\hline
\end{tabular}

(1) - Municípios existentes em janeiro de 1997.

(2) - Municípios novos criados depois de janeiro de 1997.

(3) - Municípios passíveis de reeleição; em outubro de 2000, 54 municípios recém-emancipados elegeram os seus Prefeitos pela primeira vez.

Fonte: Bremaeker e dados do TSE.

\section{QUADRO 13}

Prefeitas eleitas em 1992, 1996 e 2000, por região.\#

\begin{tabular}{|c|c|c|c|c|c|c|c|c|c|}
\hline \multirow[b]{2}{*}{$\begin{array}{c}\text { Regiã } \\
o\end{array}$} & \multicolumn{3}{|c|}{1992} & \multicolumn{3}{|c|}{1996} & \multicolumn{3}{|c|}{$2000 *$} \\
\hline & $\begin{array}{r}\left(\mathrm{N}^{\circ} \cdot \mathrm{de}\right. \\
\text { municípios) }\end{array}$ & $\mathbf{N}^{\circ}$ & $\%$ & $\begin{array}{r}\left(\mathrm{N}^{\circ} \mathrm{de}\right. \\
\text { municípios } \\
)\end{array}$ & $\mathbf{N}^{\circ}$ & $\%$ & $\begin{array}{r}\left(\mathrm{N}^{\circ} \mathrm{de}\right. \\
\text { municípios) }\end{array}$ & $\mathbf{N}^{\circ}$ & $\%$ \\
\hline Norte & 398 & 19 & $4,8 \%$ & 449 & 92 & $20,5 \%$ & 449 & 34 & $7,6 \%$ \\
\hline Nordeste & 1.558 & 92 & $4,9 \%$ & 1.787 & 153 & $8,6 \%$ & 1.791 & 149 & $8,3 \%$ \\
\hline Sudeste & 1.553 & 38 & $2,5 \%$ & 1.666 & 64 & $3,8 \%$ & 1.668 & 70 & $4,2 \%$ \\
\hline Sul & 1.058 & 11 & $1,0 \%$ & 1.159 & 30 & $2,6 \%$ & 1.189 & 32 & $2,3 \%$ \\
\hline C-Oeste & 427 & 11 & $2,6 \%$ & 445 & 27 & $6,0 \%$ & 462 & 32 & $6,9 \%$ \\
\hline TOTAL & 4.974 & 171 & $3,4 \%$ & 5.506 & 302 & $5,5 \%$ & 5.559 & 317 & $5,7 \%$ \\
\hline
\end{tabular}

\# - Porcentagem de prefeitas eleitas sobre o total de municípios.

* - Inclue as 31 cidades do $2^{\circ}$ turno.

Fontes: Instituto Brasileiro de Administração Municipal, Araujo 1999 e dados do TSE em 30 de outubro de 2000. 


\section{QUADRO 14}

Prefeitas eleitas em 2000, por partido

\begin{tabular}{|l|r|r|r|}
\hline Partido & \multicolumn{1}{|c|}{$\begin{array}{c}\text { Prefeitos } \\
\text { eleitos* }\end{array}$} & \multicolumn{1}{c|}{$\begin{array}{c}\text { Mulheres } \\
\text { eleitas }\end{array}$} & \multicolumn{1}{c|}{$\begin{array}{c}\text { \% de } \\
\text { prefeitas }\end{array}$} \\
\hline PMDB & 1.257 & 59 & $4,7 \%$ \\
\hline PFL & 1.028 & 75 & $7,3 \%$ \\
\hline PSDB & 990 & 58 & $5,9 \%$ \\
\hline PPB & 618 & 32 & $5,2 \%$ \\
\hline PTB & 398 & 25 & $6,3 \%$ \\
\hline PDT & 288 & 06 & $2,1 \%$ \\
\hline PL & 234 & 09 & $3,8 \%$ \\
\hline PT & 187 & 09 & $4,8 \%$ \\
\hline PPS & 166 & 11 & $6,6 \%$ \\
\hline PSB & 133 & 13 & $9,8 \%$ \\
\hline OutroS & 260 & 20 & $7,7 \%$ \\
\hline TOTAL & $\mathbf{5 . 5 5 9}$ & $\mathbf{3 1 7}$ & $\mathbf{5 , 7 \%}$ \\
\hline
\end{tabular}

* - Inclue of 31 cidades do $2^{\circ}$ turno.

Fonte: Dados do T.S.E., em 30 outubro de 2000.

QUADRO 15

Vereadoras eleitas em 1992, 1996 e 2000, por região.\#

\begin{tabular}{|l|r|r|r|r|r|r|}
\hline & $\mathbf{1 9 9 2}$ & $\mathbf{1 9 9 6}$ & \multicolumn{2}{|c|}{$\mathbf{2 0 0 0}$} \\
\hline Região & $\mathbf{N}^{\mathbf{0}}$ & $\mathbf{\%}$ & $\mathbf{N}^{\mathbf{0}}$ & $\mathbf{\%}$ & $\mathbf{N}^{\mathbf{0}}$ & $\mathbf{\%}$ \\
\hline Norte & $\mathbf{4 3 6}$ & $11,2 \%$ & 613 & $14,0 \%$ & 625 & $13,9 \%$ \\
\hline Nordeste & 1.629 & $9,1 \%$ & 2.498 & $13,0 \%$ & 2.569 & $13,1 \%$ \\
\hline Sudeste & 1.193 & $6,1 \%$ & 1.774 & $9,3 \%$ & 1.953 & $10,1 \%$ \\
\hline Sul & 537 & $5,1 \%$ & 1.096 & $9,5 \%$ & 1.248 & $10,3 \%$ \\
\hline Centro-Oeste & 157 & $7,9 \%$ & 555 & $12,9 \%$ & 605 & $13,0 \%$ \\
\hline TOTAL & $\mathbf{3 . 9 5 2}$ & $\mathbf{7 , 4 \%}$ & $\mathbf{6 . 5 3 6}$ & $\mathbf{1 1 , 2 \%}$ & $\mathbf{7 . 0 0 0}$ & $\mathbf{1 1 , 6 \%}$ \\
\hline
\end{tabular}

\# - Porcentagem de vereadoras eleitas sobre o total de veradores.

* Dados para Goiás não disponíveis para a eleição de 1992.

Fontes: Instituto Brasileiro de Administração Municipal Araújo 2000, e dados do TSE em 27 de outubro de 2000.

QUADRO 16

Vereadoras eleitas em 2000, por partido

\begin{tabular}{|l|r|r|r|}
\hline \multicolumn{1}{|c|}{ Partido } & \multicolumn{1}{c|}{$\begin{array}{c}\mathbf{N}^{\mathbf{0}} \text { de } \\
\text { Vereadores }\end{array}$} & $\begin{array}{c}\text { Vereadoras } \\
\text { eleitas }\end{array}$ & $\begin{array}{c}\text { \% de } \\
\text { Mulheres }\end{array}$ \\
\hline PMDB & 11.373 & 1.333 & $11,7 \%$ \\
\hline PFL & 9.649 & 1.164 & $12,1 \%$ \\
\hline PSDB & 8.518 & 1.010 & $11,6 \%$ \\
\hline PPB & 7.064 & 835 & $11,8 \%$ \\
\hline PTB & 4.989 & 583 & $11,7 \%$ \\
\hline PDT & 3.765 & 374 & $9,9 \%$ \\
\hline PL & 2.890 & 322 & $11,1 \%$ \\
\hline PT & 2.485 & 350 & $14,1 \%$ \\
\hline PPS & 2.564 & 282 & $11,0 \%$ \\
\hline PSB & 1.722 & 194 & $11,3 \%$ \\
\hline Outros & 5.268 & 553 & $10,5 \%$ \\
\hline TOTAL & $\mathbf{6 0 . 2 8 7}$ & $\mathbf{7 . 0 0 0}$ & $\mathbf{1 1 , 6 \%}$ \\
\hline
\end{tabular}

Fonte: Dados do T.S.E em 27 de outubro de 2000. 


\section{QUADRO 17}

As eleições municipais no Brasil

Resultados do primeiro e segundo turnos das eleições municipais de 2000, em 11 capitais e 20 outras cidades grandes. (\%)

\begin{tabular}{|c|c|c|c|c|c|c|c|c|c|c|c|c|c|c|c|c|c|c|c|}
\hline \multirow[b]{2}{*}{ Cidade } & \multirow[b]{2}{*}{ Est. } & \multicolumn{9}{|c|}{ Resultados do $1^{\circ}$ turno, 01 de Outubro de 2000} & \multicolumn{9}{|c|}{ Resultados do $2^{\circ}$ turno, 29 de Outubro de 2000} \\
\hline & & PMDB & PFL & PPB & PSDB & PDT & PTB & $\mathrm{PT}$ & PSB & Out. & PMDB & PFL & PPB & PSDB & PDT & PTB & PT & PSB & \begin{tabular}{|l|l} 
Out. \\
\end{tabular} \\
\hline Belém & PA & & & & & & & $\underline{43}$ & & 30 & & & & & & & $\underline{51}$ & & 49 \\
\hline B. Horizonte & MG & & & & 31 & & & & $\underline{44}$ & & & & & 45 & & & & & $\underline{55}$ \\
\hline Curitiba & PR & & $\underline{44}$ & & & & & 35 & & & & $\underline{51}$ & & & & & 49 & & \\
\hline Fortaleza & CE & $\underline{33}$ & & & & & & & & 30 & $\underline{54}$ & & & & & & & & 46 \\
\hline Goiânia & GO & & & & & & 30 & $\underline{37}$ & & & & & & & & 44 & $\underline{56}$ & & \\
\hline & & & & & & & & & & & & & & & & & & & \\
\hline Maceió & $\mathrm{AL}$ & & & & & & & & $\underline{44}$ & 22 & & & & & & & & $\underline{61}$ & 39 \\
\hline Manaus & $\mathrm{AM}$ & & & & & & & & & $47^{*}$ & & & & & & & & & $51^{*}$ \\
\hline P.Alegre & RS & & & & & 20 & & $\underline{49}$ & & & & & & & 36 & & $\underline{64}$ & & \\
\hline Recife & PE & & 49 & & & & & $\overline{36}$ & & & & 49 & & & & & $\underline{51}$ & & \\
\hline Rio & RJ & & $\underline{35}$ & & & & 23 & & & & & 49 & & & & $\underline{51}$ & & & \\
\hline São Paulo & $\mathrm{SP}$ & & & 17 & & & & $\underline{38}$ & & & & & 41 & & & & $\underline{59}$ & & \\
\hline Belforțd Roxo & $\mathrm{RJ}$ & & & & 41 & & & & & $\underline{49}$ & & & & 43 & & & & & 57 \\
\hline Campinas & $\mathrm{SP}$ & & & & 22 & & & 39 & & & & & & 40 & & & 60 & & \\
\hline Canoas & RS & & & & $3 \underline{39}$ & & & 30 & & & & & & $\underline{51}$ & & & 49 & & \\
\hline Caxias do Sul & RS & 43 & & & & & & $\underline{48}$ & & & 49 & & & & & & $\underline{51}$ & & \\
\hline & & & & & & & & & & & & & & & & & & & \\
\hline Contagem & MG & 35 & & & $\underline{48}$ & & & & & & 41 & & & $\underline{59}$ & & & & & \\
\hline Diadema & $\mathrm{SP}$ & & & & & & & $\underline{35}$ & & 35 & & & & & & & $\underline{53}$ & & 47 \\
\hline Guarulhos & SP & & & & & & & $\underline{43}$ & & 28 & & & & & & & $\underline{51}$ & & 49 \\
\hline Jaboatão & PE & & & & 31 & & & & & 39 & & & & 37 & & & & & $\underline{63}$ \\
\hline Juiz de Fora & MG & 33 & $\underline{35}$ & & & & & & & & $\underline{55}$ & 45 & & & & & & & \\
\hline & & & & & & & & & & & & & & & & & & & \\
\hline Londrina & PR & & & & & 27 & & 27 & & & & & & & 36 & & 64 & & \\
\hline Maringá & $\mathrm{PR}$ & & & & & & 25 & $\overline{26}$ & & & & & & & & 30 & $\overline{70}$ & & \\
\hline Mauá & SP & & & & 37 & & & $4 \underline{46}$ & & & & & & 47 & & & $\underline{53}$ & & \\
\hline Mogi Cruzes & $\mathrm{SP}$ & 23 & & & $\underline{44}$ & & & & & & 44 & & & $\underline{56}$ & & & & & \\
\hline Niterói & RJ & 31 & & & & $\underline{49}$ & & & & & 42 & & & & $5 \underline{58}$ & & & & \\
\hline & & & & & & & & & & & & & & & & & & & \\
\hline Olinda & $\mathrm{PE}$ & $3 \underline{36}$ & & & & & & & & 31 & 48 & & & & & & & & $\underline{52}$ \\
\hline Pelotas & $\mathrm{RS}$ & & & 27 & & & & $\underline{29}$ & & & & & 47 & & & & $\underline{53}$ & & \\
\hline Santos & SP & & & 38 & & & & 44 & & & & & $\underline{52}$ & & & & 48 & & \\
\hline São Gonçalo & RJ & 38 & & & & $\underline{40}$ & & & & & 57 & & & & 43 & & & & \\
\hline S.J.Rio Preto & SP & & 26 & & & & & & & 37 & & 46 & & & & & & & $\underline{54}$ \\
\hline Uberlândia & MG & 49 & & 33 & & & & & & & 59 & & 41 & & & & & & \\
\hline Total $1^{\circ}$ lugar & & $\overline{03}$ & 04 & 00 & 03 & 02 & 00 & 13 & 02 & 04 & $\overline{04}$ & 01 & 01 & 03 & 01 & 01 & 13 & 02 & 05 \\
\hline Total $2^{\circ}$ lugar & & 06 & 01 & 04 & 05 & 02 & 03 & 03 & 00 & 04 & 05 & 04 & 03 & 05 & 03 & 02 & 03 & 00 & 06 \\
\hline Total & & 09 & 05 & 04 & 08 & 04 & 03 & 16 & 02 & 11 & 09 & 05 & 04 & 08 & 04 & 03 & 16 & 02 & 11 \\
\hline
\end{tabular}

Out - Outros partidos (PPS, PC do B, PL, PSC, PSD e PV); * - $1^{\circ}$ turno: PL (47\%) e PPS (32\%); $2^{\circ}$ turno: PPS (51\%) e PL (49\%). 
QUADRO 18

Resultados do segundo turno das eleições municipais em 2000, por partido.

\begin{tabular}{|l|r|r|r|r|}
\cline { 2 - 5 } \multicolumn{1}{c|}{} & \multicolumn{2}{c|}{ Cidades } & \multicolumn{1}{c|}{ Votos recebidos } \\
\hline Partido & Disputadas & Ganhas & Número & \multicolumn{1}{l|}{$\%$} \\
\hline PT & 16 & 13 & 6.556 .081 & $32,1 \%$ \\
\hline PMDB & 09 & 04 & 1.559 .282 & $7,6 \%$ \\
\hline PSDB & 08 & 03 & 1.354 .736 & $6,6 \%$ \\
\hline PSB & 02 & 02 & 856.451 & $4,2 \%$ \\
\hline PPS & 05 & 02 & 715.754 & $3,5 \%$ \\
\hline PFL & 05 & 01 & 2.585 .830 & $12,7 \%$ \\
\hline PPB & 04 & 01 & 2.632 .426 & $12,9 \%$ \\
\hline PTB & 03 & 01 & 1.890 .793 & $9,3 \%$ \\
\hline PDT & 04 & 01 & 721.184 & $3,5 \%$ \\
\hline PC do B & 02 & 01 & 545.010 & $2,7 \%$ \\
\hline PSC & 01 & 01 & 141.813 & $0,7 \%$ \\
\hline PL & 01 & 01 & 319.987 & $1,6 \%$ \\
\hline PSD & 01 & 00 & 316.279 & $1,5 \%$ \\
\hline PV & 01 & 00 & 212.731 & $1,0 \%$ \\
\hline TOTAL & $\mathbf{6 2}$ & $\mathbf{3 1}$ & $\mathbf{2 0 . 4 0 8 . 3 5 7}$ & $\mathbf{1 0 0 , 0 \%}$ \\
\hline “Esquerda”** & $\mathbf{3 0}$ & $\mathbf{2 1}$ & $\mathbf{9 . 6 0 7 . 2 1 1}$ & $\mathbf{4 7 , 1 \%}$ \\
\hline
\end{tabular}

"Esquerda" = PT + PSB + PPS + PDT + PC do B + PV

Fonte: Dados do TSE em 30 de outubro de 2000.

\section{BIBLIOGRAFIA}

ARAÚJO, C. (1999) As cotas para mulheres e as eleições de 1996 e 1998: analisando resultados e perspectivas. Teoria \& Sociedade. Minas Gerais, UFMG, 4:105-134.

AVELAR, L. \& LIMA, F. D. (2000) Lentas mudanças: o voto e a política tradicional. Lua Nova, 49:195-223

AZEVEDO, E., GUIMARÃES, L. \& LESSA, R. (2000) Longa agonia do PDT pode terminar com fusão. Gazeta Mercantil, 23 de outubro de 2000, p. A-9.

BACAL, C. (2001) Emancipar distritos custa caro para o País. Gazeta Mercantil, 11 de janeiro de 2001, p. A-8.

BAQUERO, M. (org.). (1997) A lógica do processo eleitoral em tempos modernos. Porto Alegre, Editora da UFRGS.

BREMAEKER, F. E. J. (2000) A reeleição dos prefeitos municipais em 2000. Rio de Janeiro, Inst. Brasileiro de Administração Municipal.

Ciro critica euforia exagerada do PT. Correio Braziliense, 2 de novembro de 2000, p. 17.

CRUZ NETTO, O. (2000) Infidelidade ajuda governo. Correio Braziliense, 5 de novembro de 2000, p. 19.

CRUZ NETTO, O. (2000) O avanço feminino. Correio Braziliense, 6 de outubro de 2000, p. 13. 
CRUZ NETTO, O. et. al. (2000) Reeleitos são minoria de prefeitos. Correio Braziliense, 8 de outubro de 2000, p. 16.

FELÍCIO, C. \& NAKAD JR., J. (2000) Reeleição é barrada em $61 \%$ das cidades. Valor, 09 de outubro de 2000 , p. A-7.

FERNANDES, D. (2000) Oposição bate Governo nas urnas por 4,9\%. O Globo, 31 de outubro de 2000 , p. 8.

FERNANDES, D. (2000) Prefeitos petistas vão administrar 23\% do PIB nacional em 17 cidades. $O$ Globo, 31 de outubro de 200, p. 4.

FERREIRA, A. N. (2000) Acabou-se o veto ideológico ao PT. Entrevista no Jornal do Brasil, 3 de novembro de 2000 , p. 4.

FLEISCHER, D. (1996) Poder local e o sistema eleitoral brasileiro. In: JUNG, W. (org.) Poder local face às eleições de 1996. São Paulo, Konrad Adenauer Stiftung, pp. 115-133.

FLEISCHER, D. (1998). Reelección a brasileña: las elecciones generales de 1998. Contribuciones , Buenos Aires, 15(4):175-195.

FRANCO, I. (2000) Fraude com educação tira votos de prefeitos. O Globo, 15 de outubro de 2000, p. 10.

FRANCO, I. (2000) Itamar, Brizola e Arraes articulam a criação de um partido. O Globo, 26 de outubro de 2000, p. 11.

FRANCO, I. \& MACEDO, A. P. (2000) Um novo mandato para $37,5 \%$ dos prefeitos. O Globo, 08 de outubro de 2000, p. 10.

FREIRE, V. (2000) PT quer fazer da Grande São Paulo uma vitrine. O Estado de São Paulo, 6 de novembro de 2000 , p. A-6.

GASPARI, E. (2000) Surra igual, só a de 1974. O Globo, 1 de novembro de 2000, p. 7.

GUEDES, G. (2000) PT tem maior número de candidatos no segundo turno. O Estado de São Paulo, 9 de outubro de 2000, p. A-8.

GUEDES, G. (2000) PSDB reelege o maior número de prefeitos. O Estado de São Paulo, 15 de outubro de 2000 , p. A-9.

GUIBU, F., OLIVEIRA, W. \& SIQUEIRA, F. PT avalia que errou com campanha light. Folha de São Paulo, 20 de outubro de 2000, p. A-11.

KOZAK, C. (2000) PC do B já conta com 91 prefeitos em todo o Brasil. Jornal do Brasil, 5 de novembro de 2000 , p. 5.

LEONEL, J. (2000) Conflitos internos devem aumentar. Folha de São Paulo, 4 de novembro de 2000 , p. A-6.

LINS, L. (2000) No país, 72 índios de elegem em 11 estados. O Globo, 6 de outubro de 2000, p. 12.

MACEDO, A. P. (2000) Poder feminino aumenta $67 \%$ nestas eleições. O Globo, 6 de outubro de 2000, p. 12.

MARQUES, J. R. \& FLEISCHER, D. (1999) De facção a partido: a evolução do PSDB (1988-1998). Brasília, Instituto Teotonio Vilela.

MOTTA, L. G. (2000) O PT e a pedagogia democrática. Gazeta Mercantil (Centro-Oeste), 20 de outubro de 2000 , p. 4.

NASSIF, L. (2000) Urna, segurança e patente. Folha de São Paulo, 16 de novembro de 2000, p. B3. 
NERY, S. (2000) A morte do PDT e a solidão de Brizola. Jornal do Brasil, 25 de outubro de 2000, p. 5.

NÊUMANNE, J. (2000) As urnas também mentem? O Estado de São Paulo, 8 de novembro de 2000, p. A-2.

NICOLAU, J. (org). (1998) Dados eleitorais do Brasil. Rio de Janeiro, Renevan.

O'NEILL, T. (1993) All Politics is Local: And Other Rules of the Game. New York, Crown Publishing Group.

OTÁVIO, C. (2000) Garotinho está de mala pronta para sair do PDT. O Globo, 22 de outubro de 2000 , p. 5.

OTÁVIO, C. (2000) Escolha de prefeito atraiu mais que reeleição de FH. O Globo, 1 de novembro de 2000 , p. 9.

PANDA, R. (2000) Bancada de vereadoras no País será 61\% maior. O Estado de São Paulo, 23 de outubro de 2000 , p. A-9.

PASSARINHO, J. (2000) O PT e o cientista. O Estado de São Paulo, 24 de outubro de 2000, p. A-2. PEREIRA JUNIOR, J. T. (2000) A urna é nossa. O Globo, 16 de novembro de 2000, p. 7.

PT é derrotado em $47 \%$ das cidades que administra hoje. Folha de São Paulo, 5 de novembro de 2000, p. A-4.

RIBEIRO, E. (2001) Preso acusado de fraude com verba do Fundef. O Globo, 8 de janeiro de 2001, p. 8.

ROTHENBURG, D. \& LAGO, R. (2000) Arranhado o poder de ACM," Correio Braziliense, 7 de outubro de 2000 , p.24.

SANTOS, W. G. (2000) A base governista ganhou. Entrevista no Jornal do Brasil, 15 de outubro de 2000 , p. 4.

SILVA, L. I. (2000) O PT saiu consagrado. Entrevista no Jornal do Brasil, 15 de outubro de 2000, p. 5

SOARES, M. (2000) Mulheres ainda se elegem pouco. Folha de São Paulo, 6 de novembro de 2000, p. A-7.

SOARES, M. (2000) Nordeste tem mais reeleição de prefeitos. Folha de São Paulo, 19 de novembro de 2000 , p. A-10.

TABAK, I. (2000) 'Zitolândia' refaz mapa político do Rio. Jornal do Brasil, 01 de novembro de 2000, p. 5.

TEIXEIRA, M. A. C. (2000) O jogo político nos municípios e as eleições. In: HOFMEISTER, W. (org.). Os municípios e as eleições de 2000. São Paulo, Konrad Adenauer Stiftung, pp. 99-125.

ZANINI, F. (2000) Para PT, perdas revelam 'problema grave'. Folha de São Paulo, 5 de novembro de 2000 , p. A-5. 